\title{
Bond Strength of Calcium Silicate-Based Sealers to Dentine Dried with Different Techniques
}

\author{
Tamer Taşdemir ${ }^{a} \quad$ Kürşat Er ${ }^{c}$ Davut Çelik ${ }^{a}$ Erhan Tahan $^{d}$ Ahmet Serper $^{\mathrm{e}}$ \\ Kadir Tolga Ceyhanlia ${ }^{a}$ Cemal Yeşilyurt ${ }^{b}$ \\ Departments of a Endodontics and ${ }^{b}$ Restorative Dentistry, Faculty of Dentistry, Karadeniz Technical University, \\ Trabzon, ' Department of Endodontics, Faculty of Dentistry, Akdeniz University, Antalya, dDepartment of \\ Endodontics, Faculty of Dentistry, Recep Tayyip Erdoğan University, Rize, and eDepartment of Endodontics, \\ Faculty of Dentistry, Hacettepe University, Ankara, Turkey
}

\section{Key Words}

Push-out bond strength - Calcium silicate sealers - Root canal drying

\begin{abstract}
Objective: To assess the influence of various canal-drying techniques on the push-out bond strength between radicular dentine and both MTA Fillapex and iRoot SP sealers. Materials and Methods: Eighty extracted single-root teeth were instrumented with ProTaper Universal rotary instruments to a size F4. The teeth were randomly assigned to 1 of 4 groups as follows: group 1, excess fluid in the canals was removed using a Luer vacuum adapter; group 2, the canals were dried with a single paper point; group 3, the canals were dried with 3-5 paper points, and group 4, the canals were rinsed with $95 \%$ ethanol and then dried with 3-5 paper points. In each group, the specimens were subgrouped according to root canal sealer into either subgroup A (MTA Fillapex) or subgroup B (iRoot SP sealer). Horizontal sections (thickness $1 \pm 0.1 \mathrm{~mm}$ ) were obtained from each specimen and a push-out test was performed using a universal testing machine at a crosshead speed of $1 \mathrm{~mm} / \mathrm{min}$ on root slices. Statistical analysis was done using the Kruskal-Wallis test
\end{abstract}

\begin{tabular}{ll}
\hline KARGER & $\begin{array}{l}\text { ( } 2014 \text { S. Karger AG, Basel } \\
1011-7571 / 14 / 0234-0373 \$ 39.50 / 0\end{array}$ \\
$\begin{array}{l}\text { E-Mail karger@karger.com } \\
\text { www.karger.com/mpp }\end{array}$ & $\begin{array}{l}\text { This is an Open Access article licensed under the terms of the } \\
\text { Creative Commons Attribution-NonCommercial } 3.0 \text { Un- } \\
\text { ported license (CC BY-NC) (www.karger.com/OA-license), } \\
\text { applicable to the online version of the article only. Distribu- } \\
\text { tion permitted for non-commercial purposes only. }\end{array}$
\end{tabular}

and Dunn's test for pair-wise comparisons. $\mathrm{p}<0.05$ was considered statistically significant. Results: Canals dried with only 1 paper point and obturated with the iRoot SP sealer (subgroup 2B) showed significantly higher bond strengths to the root canal wall compared to all other subgroups $(p<$ $0.05)$, except for subgroup 1B ( $p>0.05)$. Conclusions: The canal-drying technique influenced the adhesive bond strength between calcium silicate-based root canal sealers and the root canal wall.

(c) 2014 S. Karger AG, Basel

\section{Introduction}

One of the primary objectives of root canal obturation is to seal the canal system completely in such a way as to prevent the penetration of tissue fluid, bacteria and/or their products into the canal and to avoid reinfection after debridement [1]. It is generally accepted that the outcome of endodontic treatment is positively correlated with the technical quality of the root filling, which is expected to provide a hermetic seal against bacterial ingress [2-4]. Many endodontic filling materials, techniques and different types of sealers have been developed for this purpose.

Dr. Tamer Tașdemir

Karadeniz Teknik Universitesi

Dis Hekimligi Fakultesi, Endodonti Anabilim Dali

TR-61080 Trabzon (Turkey)

E-Mail tamertd72@yahoo.com 


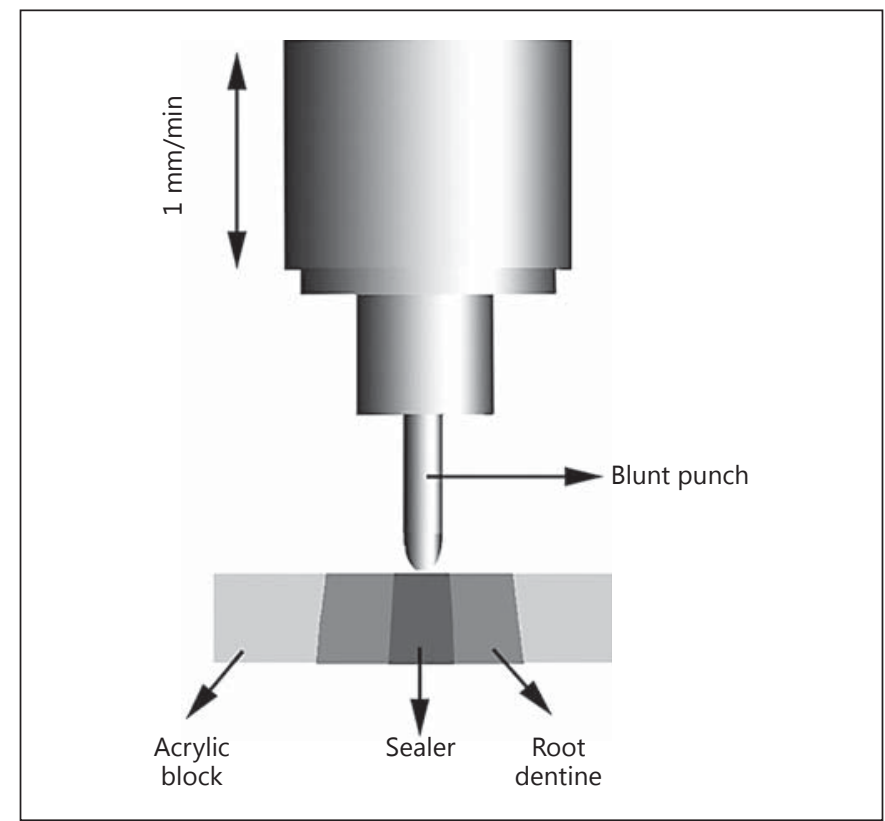

Fig. 1. Schematic representation of the setup for the assessment of bond strength.

An ideal root canal sealer provides good adhesion to the root canal wall to create an impermeable seal for the root canal system and prevent bacterial entry [5].

Recently, calcium silicate-based root canal sealers were introduced in the field of endodontics to provide all of the favourable properties of the mineral trioxide aggregate (MTA) without its negative characteristics such as the long setting time, difficult manipulation and low flow capacity [6]. MTA Fillapex (Angelus, Londrina, Brazil) has resinous components and its manufacturer claims it has excellent radiopacity, easy handling and an exact working time [7]. Although MTA Fillapex had the lowest values of flow, working and setting times, solubility and water absorption [8], it was more cytotoxic than AH Plus [9]. iRoot SP (Innovative BioCreamix Inc., Vancouver, B.C., Canada; also known as EndoSequence BC Sealer, Brasseler USA, Savannah, Ga., USA) is a new calcium silicatebased root canal sealer designed for obturating root canals with or without gutta-percha points [10] and requires the presence of water to set and harden [11].

It has been reported that the degree of residual moisture significantly affects the bond strength of these two calcium silicate-based sealers to radicular dentine [12]. However, in that study, canals were filled with gutta-percha and sealer. Consequently, it is unclear whether the failure modes in their push-out test were adhesive, i.e. between the sealer and the dentine, or cohesive, i.e. between the sealer and the core material [13]. Hence, the current study was designed to examine the capability of MTA Fillapex and iRoot SP sealers to adhere to root canal dentine subjected to different drying techniques without the gutta-percha core material. The null hypothesis was that the canal-drying technique does not affect the radicular bond strength of the tested sealers as measured by the push-out method.

\section{Materials and Methods}

\section{Specimen Preparation}

Eighty extracted sound human single-root teeth of similar size and shape were carefully selected from a large collection of teeth, scaled, pumiced and stored in $0.1 \%$ thymol solution. None of the teeth had visible root caries, fractures or cracks on examination with a $\times 4$ magnifying glass; there were no signs of internal or external resorption or calcification on radiographic images, all had a completely mature apex. The crowns were removed using a diamond disc under water-cooling and the roots were adjusted to a 15 - $\mathrm{mm}$ length. A size $10-\mathrm{K}$ file was placed in the canal until it was visualized at the apical foramen. The working length was determined by subtracting $1 \mathrm{~mm}$ from this measurement.

The root canals were instrumented with a series of ProTaper Universal (Dentsply Maillefer, Ballaigues, Switzerland) rotary files to a size F4 (40/0.06). Canals were irrigated with $2 \mathrm{ml}$ of $2.5 \%$ $\mathrm{NaOCl}$ solution after each filing. The smear layer was removed with $5 \mathrm{ml}$ of $17 \%$ EDTA for $1 \mathrm{~min}$. A final irrigation was performed with $5 \mathrm{ml}$ distilled water. The irrigant was delivered via a 30-gauge endodontic irrigation needle (KerrHawe SA, Bioggio, Switzerland) that was inserted into the canal to the working length.

Specimens were then subjected to 4 different drying techniques: (1) the excess canal moisture was removed using a Luer vacuum adapter for $5 \mathrm{~s}$ before obturation; (2) each canal was dried with a single F4 paper point (ProTaper Universal); (3) canals were dried with 3-5 paper points, with the last one appearing dry, and (4) excess moisture was removed with paper points; canals were rinsed with $95 \%$ ethanol for $10 \mathrm{~s}$ and then dried with 3-5 paper points. Canals were then entirely obturated with either MTA Fillapex (A) or iRoot SP (B) sealers. Two peri-apical radiographs were taken for each obturated root from 2 different angles to check the obturation density. Obturated roots were incubated at $37^{\circ} \mathrm{C}$ and $100 \%$ relative humidity for 1 week to allow sufficient time for the sealer to set.

\section{Push-Out Bond Strength Test}

Each root was embedded in epoxy resin in a custom-made split-ring copper mould. After setting of the epoxy resin, horizontal sections (thickness $1 \pm 0.1 \mathrm{~mm}$ ) were obtained from each specimen consecutively in an apical-to-coronal direction using a water-cooled precision saw (Micracut 125; Metkon, Bursa, Turkey). Three slices were obtained for each root sample $(n=30$ slices/ group) at 1-, 3- and 5-mm distances to the apex. Each root section was then subjected to a compressive load by a universal testing machine (Lloyd Instruments, Foreham, UK) at a crosshead speed of $1 \mathrm{~mm} / \mathrm{min}$ (fig. 1). The push-out force was applied in an apicalto-coronal direction until dislodgement of the obturating material 
Table 1. Mean push-out bond strength values

\begin{tabular}{lll}
\hline Groups & Subgroups & $\begin{array}{l}\text { Mean push- } \\
\text { out bond } \\
\text { strength } \\
( \pm \mathrm{SD}), \mathrm{MPa}\end{array}$ \\
\hline Luer vacuum adapter & $\begin{array}{l}\text { MTA Fillapex (1A) } \\
\text { iRoot SP (1B) }\end{array}$ & $\begin{array}{l}0.820 \pm 0.538 \\
2.277 \pm 1.212\end{array}$ \\
\hline Single paper point & MTA Fillapex (2A) & $1.446 \pm 0.978$ \\
& iRoot SP (2B) & $2.503 \pm 0.991$ \\
\hline 3-5 paper points & MTA Fillapex (3A) & $0.566 \pm 0.410$ \\
& iRoot SP (3B) & $1.673 \pm 0.864$ \\
\hline 95\% ethanol + paper points & $\begin{array}{l}\text { MTA Fillapex (4A) } \\
\text { iRoot SP (4B) }\end{array}$ & $0.380 \pm 0.263$ \\
& & $0.907 \pm 0.696$ \\
\hline
\end{tabular}

occurred. The force was recorded and the values were used to calculate the push-out strength in megapascals according to formula used by Bitter et al. [14].

\section{Statistical Analysis}

Statistical analysis was completed using the Kruskal-Wallis test and Dunn's test for pair-wise comparisons. $\mathrm{p}<0.05$ was considered statistically significant.

\section{Results}

The mean push-out bond strength and SD for each group are presented in table 1. Canals dried with only one paper point before obturation with iRoot SP (subgroup 2B) showed a significantly higher bond strength than the other subgroups $(\mathrm{p}<0.05)$, except for subgroup $1 \mathrm{~B}(\mathrm{p}>$ 0.05 ). The bonding strength given in table 1 is as follows: $2 \mathrm{~B} \geq 1 \mathrm{~B}>3 \mathrm{~B} \geq 2 \mathrm{~A}>4 \mathrm{~B} \geq 1 \mathrm{~A}>3 \mathrm{~A} \geq 4 \mathrm{~A}$.

\section{Discussion}

The null hypothesis, as stated in the Introduction, was rejected because the canal-drying techniques significantly affected the push-out bond strength values. The results obtained indicated that iRoot SP had a stronger bond with the root canal walls than the MTA Fillapex sealer regardless of the drying technique. This finding is consistent with previous studies that showed that MTA Fillapex had the lowest push-out bond values to root canal dentine compared to other sealers $[12,15,16]$. A probable explanation is to the different compositions of the two sealers. The iRoot SP sealer is composed mainly of calcium silicate and calcium phosphate, which require moisture to complete their hydration-setting reaction [11]. MTA Fillapex, on the other hand, has resin among its constituents, which may undergo polymerization shrinkage upon setting, thereby resulting in a reduced strength of the bond with the canal wall.

The strength of the bond between the calcium silicatebased sealers and the intra-radicular dentine was reduced in drying conditions 3 (3-5 paper points) and 4 (alcohol). This result is similar to that of a previous study which showed that excessive desiccation of dentine (conditions 3 and 4) was an impediment to bonding because an optimal amount of water is required to suspend the collagen fibrils, leaving space for penetration of the hydrophilic sealer [17].

The highest bond strength values were obtained for both sealers when the canals were dried with a single paper point. This can be explained by the findings of a study [18] which showed that curing conditions played an important role in the retention characteristics of MTA, where dry-cured MTA demonstrated a lower push-out bond strength to dentine than wet-cured MTA. Thus, it may be advantageous to leave canals slightly moist before obturating with calcium silicate-based sealers. Using similar experimental moisture conditions, Nagas et al. [12] showed that it might be advantageous to leave the canals slightly moist before obturating procedures using the same sealers. In the mentioned study [12], canals filled with gutta-percha in conjunction with sealers showed higher push-out bond strength values than the present specimens that were filled without gutta-percha cones. This may be explained by the compactable nature of gutta-percha, which can show a greater resistance to dislodgement in a push-out test design [19]. In the current study, teeth were filled only with sealer to truly reflect the bond strength between the sealer and the dentine $[13,20$, 21]. Also, while in that study [12] the sections were acquired from the coronal region, in this study they were acquired from the apical third. This difference in the resistance of the dislocation may be due to both the diameter of the canal, with more sealer in the coronal mass region, and the removal of the smear layer being more successful than in the apical region.

\section{Conclusions}

iRoot SP had a greater bond strength to dentine than MTA Fillapex. The bond strength was affected by the canal-drying technique. 


\section{References}

1 ElAyouti A, Achleithner C, Löst C, et al: Homogeneity and adaptation of a new gutta-percha paste to root canal walls. J Endod 2005;31: 687-690.

$>2$ Dugas NN, Lawrence HP, Teplitsky PE, et al: Periapical health and treatment quality assessment of root filled teeth in two Canadian populations. Int Endod J 2003;36:181-192.

-3 Kalender A, Orhan K, Aksoy U, et al: Influence of the quality of endodontic treatment and coronal restorations on the prevalence of apical periodontitis in a Turkish Cypriot population. Med Princ Pract 2013;22:173-177.

$\checkmark 4$ Ureyen Kaya B, Kececi AD, Guldas HE, et al: A retrospective radiographic study of coronal-periapical status and root canal filling quality in a selected adult Turkish population. Med Princ Pract 2013;22:334-339.

$>5$ Viapiana R, Guerreiro-Tanomaru J, Tanomaru-Filho $\mathrm{M}$, et al: Interface of dentine to root canal sealers. J Dent 2014;42:336-350.

-6 Aguilar FG, Roberti Garcia LF, Panzeri Piresde-Souza FC: Biocompatibility of new calcium aluminate cement (EndoBinder). J Endod 2012;38:367-371

7 Morgental RD, Vier-Pelisser FV, Oliveira SD, et al: Antibacterial activity of two MTA-based root canal sealers. Int Endod J 2011;44:11281133.
8 Vitti RP, Prati C, Silva EJ, et al: Physical properties of MTA Fillapex sealer. J Endod 2013; 39:915-918.

$>9$ Silva EJ, Rosa TP, Herrera DR, et al: Evaluation of cytotoxicity and physicochemical properties of calcium silicate-based endodontic sealer MTA Fillapex. J Endod 2013;39: 274-277.

10 Zhang W, Li Z, Peng B: Effects of iRoot SP on mineralization-related genes expression in MG63 cells. J Endod 2010;36:1978-1982.

11 Zhang W, Li Z, Peng B: Assessment of a new root canal sealer's apical sealing ability. Oral Surg Oral Med Oral Pathol Oral Radiol Endod 2009;107:e79-e82.

12 Nagas E, Uyanik MO, Eymirli A, et al: Dentin moisture conditions affect the adhesion of root canal sealers. J Endod 2012;38:240-244.

13 Neelakantan P, Subbarao C, Subbarao CV, et al: The impact of root dentine conditioning on sealing ability and push-out bond strength of an epoxy resin root canal sealer. Int Endod J 2011;44:491-498.

14 Bitter K, Meyer-Lueckel H, Priehn K, et al: Effects of luting agent and thermocycling on bond strengths to root canal dentine. Int Endod J 2006;39:809-818.

15 Sagsen B, Ustün Y, Demirbuga S, et al: Pushout bond strength of two new calcium silicatebased endodontic sealers to root canal dentine. Int Endod J 2011;44:1088-1091.
16 Assmann E, Scarparo RK, Böttcher DE, et al: Dentin bond strength of two mineral trioxide aggregate-based and one epoxy resin-based sealers. J Endod 2012;38:219-221.

17 Lee BS, Wang CY, Fang YY, et al: A novel urethane acrylate-based root canal sealer with improved degree of conversion, cytotoxicity, bond strengths, solubility, and dimensional stability. J Endod 2011;37:246-249.

18 Gancedo-Caravia L, Garcia-Barbero E: Influence of humidity and setting time on the push-out strength of mineral trioxide aggregate obturations. J Endod 2006;32:894-896

19 Fisher MA, Berzins DW, Bahcall JK: An in vitro comparison of bond strength of various obturation materials to root canal dentin using a push-out test design. J Endod 2007;33: 856-858.

20 Neelakantan P, Varughese AA, Sharma S, et al: Continuous chelation irrigation improves the adhesion of epoxy resin-based root canal sealer to root dentine. Int Endod J 2012;45: 1097-1102.

21 De-Deus G, Accorsi-Mendonça T, de Carvalho e Silva L, et al: Self-adjusting file cleaning-shaping-irrigation system improves rootfilling bond strength. J Endod 2013;39:254257. 